\title{
THE FEATURES OF EXTREMISM PREVENTION AMONG YOUNG PEOPLE
}

\author{
Pyotr P. Muraev \\ Volgograd State University, Volgograd, Russian Federation \\ Dmitry N. Yakovlev \\ Department of the Ministry of Internal Affairs of the Russian Federation for the City of Volgograd, \\ Volgograd, Russian Federation \\ Viktoriya V. Shalimova \\ Department of the Ministry of Internal Affairs of the Russian Federation for the City of Volgograd, \\ Volgograd, Russian Federation
}

Introduction: the development of the market economy at the present stage of the Russian state has directly affected the criminological situation among young people. The extent of crime among this category of population is currently almost unchanged. The increase in the level of its public danger and the manifestation of new forms of criminal behavior of extremist orientation sharply exacerbate the criminal situation in the regions, including the Volgograd region. In this regard, the urgency of effective measures to prevent this negative phenomenon is increasing. The purpose of the paper: to characterize the current state of prevention of extremism among young people. Tasks: to assess the prevention of extremism among young people; to identify promising areas of systemic interaction between the main subjects of prevention of juvenile and youth extremism; to offer recommendations on the need to introduce organizational and socio-psychological directions of countering extremist influences on the young person into the academic and educational processes. Methods: the authors used the general scientific, systemic, and institutional research methods, as well as the methods of legal statistics, which allowed them to solve the tasks set by the research team. Results: the problems of extremism among young people are characterized, the promising directions of its prevention are identified, and the results of the fight against youth extremism in Volgograd are shown using the methods of legal statistics. Conclusions: in order to improve the efficiency of the prevention of youth extremism within the territory of Volgograd and the region the authors suggest in a coordinated manner with the participation of all actors of prevention to solve the employment problem of young people sentenced to penalties not involving incarceration; to systematically organize events in conjunction with the operational units, 간 to identify and separate criminal gangs, involving the youth in their illegal activities; to regularly conduct preventive ¿ work with the parents and legal representatives of adolescents, especially those who are in a difficult life situation. . Key words: extremism, prevention, youth, extremist organizations, informal youth groups, terrorism.

Citation. Muraev P.P., Yakovlev D.N., Shalimova V.V. The Features of Extremism Prevention Among Young People. Legal Concept, 2020, vol. 19, no. 2, pp. 43-49. (in Russian). DOI: https://doi.org/10.15688/lc.jvolsu.2020.2.6

\section{ОСОБЕННОСТИ ПРОФИЛАКТИКИ ЭКСТРЕМИЗМА В МОЛОДЕЖНОЙ СРЕДЕ}

\author{
Петр Петрович Мураев \\ Волгоградский государственный университет, г. Волгоград, Российская Федерация \\ Дмитрий Николаевич Яковлев \\ Управление МВД России по городу Волгограду, г. Волгоград, Российская Федерация
}




\section{Виктория Владимировна Шалимова}

Управление МВД России по городу Волгограду, г. Волгоград, Российская Федерация

Введение: развитие рыночной экономики на современном этапе российского государства непосредственно отразилось на криминологической обстановке в молодежной среде. Масштабы преступности среди данной категории населения в настоящее время практически не уменьшаются. Повышение уровня ее общественной опасности, проявление новых форм преступного поведения экстремистской направленности резко обостряют криминальную ситуацию в регионах, включая и Волгоградскую область. В связи с этим возрастает актуальность проведения действенных мер профилактики данного негативного феномена. Цель статьи: охарактеризовать современное состояние профилактики экстремизма в молодежной среде. Задачи: дать оценку профилактики экстремизма среди молодежи; выявить перспективные направления системного взаимодействия основных субъектов профилактики несовершеннолетнего и молодежного экстремизма; предложить рекомендации по необходимости внедрения в учебный и воспитательный процессы организационных и социально-психологических направлений противодействия экстремистским влияниям на личность молодого человека. Методы: в статье авторы использовали общенаучные методы, такие как: системный, институциональный методы исследования, а также методы правовой статистики, позволившие решить поставленные исследовательским коллективом задачи. Результаты: охарактеризованы проблемы экстремизма в молодежной среде, выявлены перспективные направления его профилактики, а также с помощью методов правовой статистики показаны результаты борьбы с молодежным экстремизмом в г. Волгограде. Выводы: в целях повышения эффективности профилактики молодежного экстремизма на территории Волгограда и области авторы статьи предлагают на скоординированной основе с участием всех субъектов профилактики решать проблемы занятости молодых граждан, осужденных к мерам наказания и не связанных с лишением свободы; систематически организовывать мероприятия совместно с оперативными подразделениями в целях выявления и разобщения преступных группировок, вовлекающих молодежь в их противоправную деятельность; регулярно проводить профилактическую работу с родителями и законными представителями подростковой молодежи, особенно тех, кто находится в трудной жизненной ситуации.

Ключевые слова: экстремизм, профилактика, молодежь, экстремистские организации, неформальные молодежные группы, терроризм.

Цитирование. Мураев П. П., Яковлев Д. Н., Шалимова В. В. Особенности профилактики экстремизма в молодежной среде // Legal Concept = Правовая парадигма. -2020 . - T. 19, № 2. - C. 43-49. - DOI: https://doi.org/ 10.15688/lc.jvolsu.2020.2.6

\section{Введение}

Анализ статистических данных правонарушений и преступлений молодежи в Российской Федерации показывает негативные тенденции в данной сфере. Так, согласно статистике Главного информационного центра МВД по России с 1994-1996 г., судимость учащихся и студентов увеличилось с 48,5 до 61,2 тысяч человек (на 25,7 \%) в 1996 г., а в 2019 г. данный показатель составил 59,16 тыс. человек, что подтверждает наличие проблемы профилактики преступлений в молодежной среде более 25 лет. Это обусловлено тем, что увеличивается количество неформальных молодежных организаций с преобладанием корыстной ориентации. Для этого необходимо уделить особое внимание проведению профилактики данного негативного феномена, включая и профилактику преступлений экстремистской направленности.

\section{Профилактика экстремизма в молодежной среде как перспективное направление обеспечения государственной и общественной безопасности}

Национальная безопасность Российской Федерации регламентирует профилактическую деятельность правоохранительной системы среди молодежи в рамках реализации одного из приоритетных направлений обеспечения национальной безопасности «Государственная и общественная безопасность», что в конечном счете способствует защите конституционного строя и территориальной целостности российского государства.

Профилактические мероприятия в сфере молодежного экстремизма зависят от правильного понимания этого сложного общественного явления [8, с. 93]. Так, прежде все- 
го необходимо знать смысл и содержание концепта «экстремизм», означающего приверженность к крайним идеям, взглядам и действиям. Ему присуще насилие или его угроза, однобокость в восприятии проблем и поиске путей их решения, стремление навязать свои принципы и взгляды, фанатизм, опора на чувства, инстинкты. Содержание данного понятия закреплено в ст. 1 Федерального закона № 114 от 25.07.2002 г. «О противодействии экстремистской деятельности». В Уголовном кодексе РФ под преступлениями экстремистской направленности понимаются те из них, которые совершаются по политическим, идеологическим, религиозным мотивам или на основе национальной ненависти или вражды. Уголовная ответственность за преступления экстремистской направленности по статьям 148,149, ч. $1213,243,244,280,282$ наступает с 16 лет [10, с. 197].

Профилактика экстремизма регламентируется следующими основными правовыми документами: Конституция Российской Федерации, Федеральный закон № 114 от 25.07.2002 г. «О противодействии экстремистской деятельности», Указ Президента Российской Федерации № 310 от 23.03.1995 г. «О мерах по обеспечению согласованных действий органов государственной власти в борьбе с проявлениями фашизма и иных форм политического экстремизма в Российской Федерации», Уголовный кодекс Российской Федерации, Стратегия национальной безопасности Российской Федерации до 2020 года», Указ Президента Российской Федерации № 683 от 31.12.2015 года.

Понимая причины зарождения источников экстремизма среди молодежи, необходимо внести в учебно-воспитательный процесс организационные, социально-психологические направления противодействия экстремистским взглядам молодой личности. Причины возникновения экстремизма среди молодежи находятся не столько в общественных условиях, сколько в интеллектуальной и нравственной ограниченности личности, отстаивающей подобные взгляды. Особенность экстремизма молодого поколения вызвано прежде всего возрастом. Наивысшая активность проявления преступного поведения - в возрасте от 15 до 18 лет [1, с. 307], сам же возраст членов экстремистских группировок колеблется от 12-13 до 30 лет.

Одним из важнейших направлений борьбы с молодежным экстремизмом является профилактика, то есть принятие мер, направленных на предупреждение экстремистской деятельности, в том числе на выявление и последующее устранение причин и условий, способствующих осуществлению экстремистской деятельности. Это обусловлено тем, что, по данным МВД России, в среднем до $80 \%$ участников группировок экстремистской направленности составляют лица в возрасте до 30 лет [5, с. 104].

В контексте данной проблематики целесообразно рассмотреть деятельность молодежных группировок, которая далеко не всегда способствует обеспечению государственной и общественной безопасности России.

В действиях уличной экстремистской группировки отсутствует глубокая приверженность какой-то определенной идеологии; действия, идущие вразрез уголовному законодательству, в большей степени административные правонарушения или преступления, совершаемые лицами этих группировок, чаще всего являются просто проявлением агрессии [3, с. 174].

Неформальные группы - это группы, существование которых определяется не инструкциями каких-то инстанций, а активностью членов этих групп. Такие молодежные объединения, можно условно представить несколькими социальными группами общественных объединений - это антисоциальные, асоциальные, просоциальные.

Антисоциальные группы - это группировки или объединения, существующие по территориальному признаку, организации экстремистской направленности: политической, националистическо-расистской, религиозной.

Асоциальные группы - это наиболее распространенные группы, стоящие в стороне от каких либо социальных проблем, не представляющие угрозу для общества.

Просоциальные группы - группы, которым свойственна социально одобряемая деятельность, социальная активность, примером этому может быть участие в решении экологических проблем, охране памятников и т. д.

В целях профилактики экстремизма в молодежной среде следует различать груп- 
пировки экстремистской направленности от неформальных молодежных объединений [4, c. 121]. В последних отсутствует четкое членство, их принято рассматривать как формирования, объединяющие в себе молодежь по признаку субкультуры.

Радикальные объединения обычно декларируют, против чего они борются и какие законные или незаконные методы собираются использовать. Так, например, группировки скинхедов в большинстве случаев состоят из числа молодежи, проживающей в одном микрорайоне либо обучающейся в одном учебном заведении. «Неформальные» лидеры, имеющие первоначально хулиганские мотивы совершения противоправных действий в отношении иностранных граждан, объединяют вокруг себя молодежь, впоследствии пропагандируя идеологию радикальных структур, подстрекают лиц, не имеющих устойчивого мировоззрения, к совершению преступлений на почве национальной и расовой вражды [9, с. 140].

Проведенные проверки в субъектах Российской Федерации выявили наличие неформальных объединений экстремистской направленности с участием молодежи, подрывающих национальную безопасность России: скинхеды, Русское национальное единство, Национально-державная партия России, Национально-большевистская партия. Их идеологической основой является пропаганда расовой и национальной исключительности, стремление к вытеснению, а в ряде случаев и физическому уничтожению неславянских национальностей на территории России, что является прямым нарушением Конституции РФ, а также влечет за собой ответственность, предусмотренную уголовным законодательством РФ.

\section{Особенности профилактики молодежного экстремизма в Волгоградском регионе}

Профилактика экстремизма и терроризма в молодежной среде, а также охрана общественного порядка граждан являются одними из приоритетных направлений органов полиции [7, с. 36]. Главным Управлением МВД России по Волгоградской области, Управле- нием МВД России по городу Волгограду и ОП Управления МВД России по городу Волгограду совместно с заинтересованными учреждениями и ведомствами предпринимались меры по стабилизации оперативной обстановки среди несовершеннолетних в городе и предупреждению подростковой преступности.

В 2019 г. в Волгоградском регионе организован и проведен комплекс оперативных и профилактических мероприятий, которые направлены на стабилизацию криминогенной обстановки в молодежной среде. Всего на территории Волгограда и области осуществляют свою деятельность 63 национальных общественных объединения, из них зарегистрированы 55 национальных общественных объединений и 6 религиозных организаций (по городу 46 и 3 соответственно).

Участковыми уполномоченными полиции регулярно проводятся профилактические мероприятия по недопущению межнациональных конфликтов в общежитиях вузов: 9 общежитий, в которых проживают чуть более 1000 иностранных студентов без учета представителей стран СНГ (всего в вузах города обучается 3000 иностранных студентов, каждый третий из них - представитель страны СНГ).

До иностранных студентов доводится информация о мерах по соблюдению личной безопасности, даются контактные телефоны территориальных отделов полиции, разъясняется порядок обращения в ОВД по всем фактам совершения противоправных действий в отношении них.

В отношении лиц, выявленных в ходе проведения оперативно-розыскных и профилактических мероприятий, проживающих без регистрации, прибывающих на территорию города Волгограда, регистрирующихся в УФМС и представляющих оперативный интерес, проводится проверка во взаимодействии с территориальными отделами полиции Управления, информационным центром, Центром по профилактике экстремизма ГУ МВД России по Волгоградской области, а также УФСБ России по Волгоградской области.

С главами национальных диаспор на постоянной основе проводятся рабочие встречи по вопросу профилактики и недопущения на территории города Волгограда экстремистских проявлений [6, с. 138]. Работа по осве- 
щению деятельности религиозных общин осуществляется в строгом соответствии с законодательством в сфере вероисповедания.

В ходе индивидуальной работы с подучетными подростками проводятся профилактические беседы в рамках общей профилактики в образовательных организациях, лекции, классные часы и т. п. [2, с. 28], в том числе об опасностях Интернета, о киберпреступниках, недопустимых контентах, вторжении сторонними лицами в частную жизнь детей и семьи. Детям разъясняется, как их собственное поведение в сети может снизить угрозу и обеспечить безопасность в Интернете.

Эффективным методом предупреждения, выявления и пресечения экстремистской деятельности, на наш взгляд, является организация и проведение рейдовых мероприятий. В 2019 г. на территории г. Волгограда инспекторами ПДН организовано и проведено 433 специализированных рейда, которые были направлены на профилактику экстремистских течений среди несовершеннолетних, выявление подростков, причисляющих себя к различным неформальным молодежным объединениям. В результате мероприятий было выявлено 7 мест концентрации несовершеннолетних, носящих неформальный характер. Организовано и проведено 15 оперативно-профилактических мероприятий, в том числе 4 , направленных на профилактику правонарушений среди несовершеннолетних, совершаемых на почве ксенофобии, национального, расового и религиозного экстремизма ${ }^{1}$.

Основой профилактической деятельности в отношении молодежи, включая и несовершеннолетних, причисляющих себя к различным неформальным молодежным течениям антиобщественной направленности, является индивидуальный подход к каждому подростку, что обусловливает необходимость изучения особенностей личности. Для предупреждения противоправного поведения молодых людей руководством отделов внутренних дел проводятся личные встречи и беседы с лицами, состоящими на учете в органах внутренних дел, и родителями подучетных. Деятельность несовершеннолетних, причисляющих себя к неформальным молодежным объединениям и течениям, в настоящее время «криминальной окраски» не имеет.

\section{Выводы}

Таким образом, в целях повышения эффективности профилактики экстремизма в молодежной среде необходимо: системно (с участием всех субъектов профилактики) решать вопрос относительно занятости несовершеннолетней молодежи, приговоренной к мерам наказания, которые не связаны с лишением свободы; повысить эффективность осуществления наблюдения за поведением несовершеннолетних, состоящих на профилактическом учете; разрабатывать и проводить совместно с оперативными подразделениями мероприятия по выявлению и разобщению преступных группировок, вовлекающих в преступную деятельность лиц несовершеннолетнего возраста; осуществлять профилактическую деятельность с родителями и законными представителями несовершеннолетних, прежде всего, находящихся в трудной жизненной ситуации или социально опасном положении; модернизировать взаимодействие всех заинтересованных ведомств и структур в вопроcax, связанных с профилактикой групповой и повторной преступности молодежи.

\section{ПРИМЕЧАНИЕ}

${ }^{1}$ Справка НMO 12.2019.

\section{СПИСОК ЛИТЕРАТУРЫ}

1. Защита прав и свобод несовершеннолетних в уголовном судопроизводстве / Н. С. Денисова [и др.] // Евразийский юридический журнал. - 2019. № 9. - С. 305-310.

2. Косяченко, В. И. Действия сотрудников полиции по обеспечению общественного порядка и общественной безопасности при проведении массовых мероприятий / В. И. Косяченко, А. В. Жуланов, В. М. Таланов // Вестник Волгоградской академии МВД России. - 2016. - № 3. - С. 26-31.

3. Косяченко, В. И. Пресечение деятельности незаконных вооруженных формирований / В. И. Косяченко, Д. А. Новохатский, С. А. Жарков // Вестник Волгоградской академии МВД России. - 2014. - № 1. C. $172-177$.

4. Мураев, П. П. Противодействие религиозному экстремизму - задача сегодняшнего дня / П. П. Мураев, П. П. Фантров // Оптимизация правовой основы противодействия преступности: к 25-ле- 
тию Конституции Российской Федерации : сб. науч. тр. по итогам Всерос. науч.-практ. конф. с междунар. участием, 2018. - С. 119-124.

5. Национальная безопасность России: контроверзы общества и государства / П. П. Фантров [и др.]. - Волгоград, 2019. - 190 с.

6. Фантров, П. П. Национально-культурные автономии и обеспечение национальной безопасности России (на примере Волгоградской области) / П. П. Фантров // Материалы Научной сессии, г. Волгоград, 25-29 апр. 2016 г. В 6 ч. Ч. 2. Право и юриспруденция. Философские науки. - Волгоград : Изд-во ВолГУ, 2016. - С. 137-139.

7. Фантров, П. П. Региональные стратегии национальной безопасности Юга России: противостояние гражданских ассоциаций криминальным угрозам / П. П. Фантров, В. М. Шинкарук // Legal Concept. - 2018. - № 2. - C. 33-38. - DOI: https:// doi.org/10.15688/lc.jvolsu.2018.2.5.

8. Фантров, П. П. Социальная политика РФ: профилактика правонарушений несовершеннолетних как направление обеспечения национальной безопасности / П. П. Фантров // Материалы Научной сессии (г. Волгоград, 20-24 апр. 2015 г.) ; Федер. гос. авт. образоват. учреждение высш. проф. образования «Волгогр. гос. ун-т». - Волгоград : Изд-во ВолГУ 2015. - С. 92-95.

9. Шинкарук, В. М. Обстоятельства, подлежащие доказыванию, по делам о вооруженном хулиганстве / В. М. Шинкарук // Вестник Волгоградского государственного университета. Серия 5: Юриспруденция. - 2012. - № 1. - С. 138-142.

10. Шинкарук, В. М. Проблемы законодательной регламентации признаков субъективной стороны хулиганства / В. М. Шинкарук // Вестник Волгоградского государственного университета. Серия 5: Юриспруденция. - 2016. - № 1. - С. 194-199.

\section{REFERENCES}

1. Denisova N.S., Fantrov P.P., Solovyova N.A., Solovyova P.V. Zashchita prav i svobod nesovershennoletnikh $\mathrm{v}$ ugolovnom sudoproizvodstve [Protection of the Rights and Freedoms of Minors in Criminal Proceedings]. Evrazijskiy yuridicheskiy zhurnal [Eurasian Law Journal], 2019, no. 9, pp. 305-310.

2. Kosyachenko V. I., ZhulanovA.V., Talanov V. M. Deystviya sotrudnikov politsii po obespecheniyu obshchestvennogo poryadka i obshchestvennoy bezopasnosti pri provedenii massovykh meropriyatiy [Police Officers to Ensure Public Order and Public Security During Mass Events]. Vestnik Volgogradskoy akademii MVD Rossii [Bulletin of Volgograd Academy of MIA of Russia], 2016, no. 3, pp. 26-31.
3. Kosyachenko V.I., Novokhatsky D.A., Zharkov S.A. Presechenie deyatelnosti nezakonnykh vooruzhennykh formirovaniy [Suppression of Activity of Illegal Armed Formations]. Vestnik Volgogradskoy akademii MVD Rossii [Bulletin of the Volgograd Academy of MIA of Russia], 2014, no. 1, pp. 172-177.

4. Muraev P.P., Fantrov P.P. Protivodeystvie religioznomu ekstremizmu - zadacha segodnyashnego dnya [Combating Religious Extremism - the Challenge of the Day]. Optimizaciya pravovoy osnovy protivodeystviya prestupnosti: $k$ 25-letiyu Konstitutsii Rossiyskoy Federatsii sbornik nauchnykh trudov po itogam Vserossiyskoy nauchno-prakticheskoy konferentsii s mezhdunarodnym uchastiem [Optimization of the Legal Framework of Combating Crime: the $25^{\text {th }}$ Anniversary of the Constitution of the Russian Federation Collection of Scientific Papers on the Results of the All-Russian Scientific-Practical Conference with International Participation], 2018, pp. 119-124.

5. Fantrov P.P., Guhl V., Solovyova N.A., Shinkaruk V.M. Natsionalnaya bezopasnost Rossii: kontroverzy obshchestva i gosudarstva [National Security of Russia: Controversy of Society and the State]. Volgograd, 2019. 190 p.

6. Fantrov P.P. Natsionalno-kulturnye avtonomii i obespechenie natsionalnoy bezopasnosti Rossii (na primere Volgogradskoy oblasti) [National-Cultural Autonomy and National Security of Russia (on Example of the Volgograd Region)]. Materialy nauchnoy sessii, g. Volgograd, 25-29 apr. 2016 g. V 6 ch. Ch. 2 [Materials of Scientific Session, Volgograd, 25-29 April 2016. In 6 Parts. Part 2], 2016, pp. 137-139.

7. Fantrov P.P., Shinkaruk V.M. Regionalnye strategii natsionalnoy bezopasnosti Yuga Rossii: protivostoyanie grazhdanskikh assotsiatsiy kriminalnym ugrozam [Regional National Security Strategy of the South of Russia: Confrontation and Civil Association ofCriminal Threats]. Legal Concept, 2018, no. 2, pp. 33-38. DOI: https://doi.org/10.15688/lc.jvolsu.2018.2.5.

8. Fantrov P.P. Sotsialnaya politika RF: profilaktika pravonarusheniy nesovershennoletnikh kak napravlenie obespecheniya natsionalnoy bezopasnosti [Social Policy of the Russian Federation: the Prevention of Juvenile Delinquency as the Direction of National Security]. Materialy Nauchnoj sessii, g. Volgograd, 2024 apr. 2015 g. Feder. gos. avt. obrazovat. uchrezhdenie vyssh. prof. obrazovaniya «Volgogr. gos. $u n-t\rangle$ [Materials of Scientific Conference, Volgograd, 20-24 April 2015. Federal State Educational Institution of Higher Professional Education Volgograd State University]. Volgograd, Izd-vo VolGU, 2015, pp. 92-95.

9. Shinkaruk V.M. Obstoyatelstva, podlezhashchie dokazyvaniyu po delam o vooruzhennom huliganstve [The Circumstances Be Proven, in Cases of Armed Hooliganism]. Vestnik 
Volgogradskogo gosudarstvennogo universiteta. Seriya 5: Yurisprudentsiya [Vestnik of Volgograd State University. Series 5: Law], 2012, no. 1, pp. 138-142.

10. Shinkaruk V.M. Problemy zakonodatelnoy reglamentatsii priznakov subyektivnoy storony huliganstva [Problems of Legal Regulation of the Signs of the Subjective Part of Hooliganism]. Vestnik Volgogradskogo gosudarstvennogo universiteta. Seriya 5: Yurisprudentsiya [Vestnik of Volgograd State University. Series 5: Law], 2016, no. 1, pp. 194-199.

\section{Information About the Authors}

Pyotr P. Muraev, Candidate of Sciences (Jurisprudence), Associate Professor, Department of Criminal Procedure and Criminalistics, Volgograd State University, Prosp. Universitetsky, 100, 400062 Volgograd, Russian Federation, muraev@volsu.ru, https://orcid.org/0000-0002-4181-7098

Dmitry N. Yakovlev, Head of the Department of Police District Commissioners and Juvenile Affairs Division, Department of Internal Affairs of the Russian Federation for the City of Volgograd, Irkutskaya St., 20, 400074 Volgograd, Russian Federation, diakovlev26@mvd.ru, https://orcid.org/0000-0002-8176-6627

Viktoriya V. Shalimova, Senior Inspector, Department of Police District Commissioners and Juvenile Affairs Division, Department of the Ministry of Internal Affairs of the Russian Federation for the City of Volgograd, Irkutskaya St., 20, 400074 Volgograd, Russian Federation, vshalimova@mvd.ru, https://orcid.org/0000-0002-4708-5035

\section{Информация об авторах}

Петр Петрович Мураев, кандидат юридических наук, доцент кафедры уголовного процесса и криминалистики, Волгоградский государственный университет, просп. Университетский, 100, 400062 г. Волгоград, Российская Федерация, muraev@volsu.ru, https://orcid.org/0000-0002-4181-7098

Дмитрий Николаевич Яковлев, начальник ОУУП и ПДН, Управление МВД России по городу Волгограду, ул. Иркутская, 20, 400074 г. Волгоград, Российская Федерация, diakovlev26@mvd.ru, https://orcid.org/0000-0002-8176-6627

Виктория Владимировна Шалимова, старший инспектор ОУУП и ПДН, Управление МВД России по городу Волгограду, ул. Иркутская, 20, 400074 г. Волгоград, Российская Федерация, vshalimova@mvd.ru, https://orcid.org/0000-0002-4708-5035 